\title{
ProUCA-UFT: Espaço de Construção de Competências Socioemocionais
}

\author{
Rosária H. R. Nakashima ${ }^{1}$, Marilene A. F. Borges ${ }^{2}$, Georges F. dos Santos ${ }^{3}$ \\ ${ }^{1}$ Curso de História- Universidade Federal do Tocantins (UFT) \\ Av. Paraguai esq c/Rua Uxiramas, s/nº CEP: 77824-838 - Araguaína, TO - Brazil \\ ${ }^{2}$ Centro de Educação Aberta e a Distância - Universidade Federal de Ouro Preto \\ (UFOP) - Ouro Preto, MG - Brazil \\ ${ }^{3}$ Curso de Letras-Libras - Universidade Federal do Tocantins (UFT) \\ Rua 07 Qd. 15 s/nº Jardim dos Ipês CEP: 77500-000 - Porto Nacional, TO - Brazil \\ \{rosaria,george.f\} @uft.edu.br, marileneafb@yahoo.com.br
}

\begin{abstract}
This article presents some results of ProUCA-Federal University of Tocantins, focused on the training of principals, teachers and students of municipal schools for the integration of technology into school curricula, digital inclusion and the appropriation of technological and pedagogical language of laptops. It revealed that the actions proposed by the training course and developed in schools favored the construction of different socioemotional skills for elementary school students: extroversion; openness to new experiences; emotional stability; kindness and conscientiousness. This study points to the need for further research on the development of socio-emotional skills in the pedagogical actions supported by digital technologies.
\end{abstract}

Resumo. Este artigo apresenta alguns resultados do ProUCA-Universidade Federal do Tocantins, voltado para a formação de diretores, professores $e$ estudantes de escolas municipais, para a integração das tecnologias ao currículo escolar, a inclusão digital e a apropriação da linguagem tecnológica e pedagógica dos laptops. Revelou que as ações propostas pelo curso de formação, desenvolvidas nas escolas, favoreceram a construção de diferentes competências socioemocionais pelos estudantes do ensino fundamental: extroversão; abertura a novas experiências; estabilidade emocional; amabilidade e conscienciosidade. Este estudo aponta para a necessidade de aprofundamento das pesquisas sobre o desenvolvimento de competências socioemocionais nas ações pedagógicas apoiadas por tecnologias digitais.

\section{Introdução}

A integração das tecnologias digitais de informação e comunicação (TDIC) ao currículo tem sido o foco de diversos estudos, dentre eles, os "Padrões de Competência em TIC para Professores", que reconhecem tal importância para que os estudantes tenham a oportunidade de ampliar complexas habilidades vinculadas aos conteúdos específicos, com apoio das TDIC e da ação docente [Unesco 2008]. Diante dessas demandas, o 
Programa Um Computador por Aluno, vinculado à Universidade Federal do Tocantins (ProUCA/UFT), realizou entre 2013 e 2014 um processo de formação em rede, integrando Ministério de Educação (MEC); a Pontifícia Universidade Católica de São Paulo (PUC-SP); a Universidade Federal de Ouro Preto (UFOP); a União dos Dirigentes Municipais do Tocantins (UNDIME-TO) e a Secretaria de Educação do Estado do Tocantins (SEDUC-TO). Dentre seus objetivos destacou-se a formação de professores e diretores para o uso do laptop em práticas pedagógicas, que privilegiassem a aprendizagem dos estudantes, baseada na construção cooperativa do conhecimento.

Observou-se que novas práticas pedagógicas com o uso dos laptops foram efetivadas nas salas de aulas e alguns fatos chamaram a atenção dos professores provocando questionamentos como: Por que os alunos se ajudam e são solidários com os colegas que não estão conseguindo fazer a atividade? Por que eles apresentam mais autonomia na realização das atividades e gostam tanto de utilizar o laptop? As pedagógicas práticas pedagógicas com o uso dos laptops estariam promovendo a aquisição de outras competências, além das cognitivas?

Neste trabalho, serão apresentadas algumas evidências de competências, que não estavam previstas no projeto, e que emergiram a partir do uso dos laptops pelos estudantes do $1^{\circ}$ ao $5^{\circ}$ ano do ensino fundamental, das escolas municipais do Tocantins, participantes deste estudo.

\section{Competências socioemocionais no processo de aprendizagem}

O desenvolvimento do educando, assegurando-lhe formação básica comum para o exercício da cidadania e para o progresso no trabalho e em estudos posteriores, está previsto no artigo 22 da Lei de Diretrizes e Bases 9394/96 [Brasil, 1996]. No processo de formação dos alunos do ensino fundamental, "o desenvolvimento está marcado por interesses próprios, relacionado aos seus aspectos físico, emocional, social e cognitivo, em constante interação" [Brasil 2013, p. 110]. Em outras palavras, todos têm o direito de construir conhecimentos escolares, valores, atitudes e competências derivados dos conteúdos curriculares e interações ocorridas no processo educativo.

O enfrentamento dos desafios e o aproveitamento das potencialidades do século XXI exigem formação integral de cidadãos, articulando competências cognitivas e socioemocionais. De acordo com Santos e Primi (2014, p. 11):

Pesquisas conduzidas por economistas, psicólogos e educadores nas últimas décadas revelam que competências como persistência, responsabilidade e cooperação têm impacto significativo sobre o desempenho dos indivíduos na escola e fora dela, sendo tão importantes quanto as habilidades cognitivas para a obtenção de bons resultados em diversas esferas do bem-estar individual e coletivo, como grau de escolaridade, emprego e saúde. Essas pesquisas também revelam que indivíduos que têm competências socioemocionais mais desenvolvidas apresentam maior facilidade de aprender os conteúdos escolares. 
A relação de competências com aspectos emocionais e sociais não é algo inédito. Carneiro e Ziviani (1998) citam alguns autores que podem ser consultados para aprofundamento dos conceitos de inteligência social [Thorndike 1920; Wechsler 1950; Guilford 1968]; inteligência prática e inteligência bem sucedida [Sternberg 1985, 1997]; inteligência interpessoal [Gardner 1994]; inteligência emocional [Salovey e Mayer 1990; Goleman 1996] e inteligência moral [Boss 1994].

A discussão sobre competências socioemocionais ganhou novo destaque em março de 2014, durante o Fórum Internacional de Políticas Públicas ${ }^{1}$, com o tema "Educar para as competências do Século 21" de acordo com a Organização para a Cooperação e Desenvolvimento Econômico (OCDE, 2014, p. 7, tradução nossa):

\begin{abstract}
A educação pode preparar os indivíduos, melhorando suas habilidades cognitivas que se refletem, por exemplo, na alfabetização, matemática e habilidades para resolver problemas. Além disso, a educação pode melhorar as habilidades sociais e emocionais, tais como perseverança, presteza e autoestima. Evidências recentes sugerem que as habilidades sociais e emocionais podem ser tão poderosas quanto as habilidades cognitivas em promover o sucesso dos indivíduos, permanecendo flexível além da infância.
\end{abstract}

Outros estudos [John e Srivastava 1999; Almlund et al. 2011; Santos e Primi 2014] revelam que há "Cinco Grandes Fatores" (Big Five) eficazes para analisar a personalidade humana, a saber: 1. Abertura a novas experiências: enquanto tendência a estar aberto a novas experiências estéticas, culturais e intelectuais, isto é, está relacionada à curiosidade, imaginação, criatividade e prazer pela aprendizagem. 2. Conscienciosidade: como tendência a ser organizado e esforçado, ou seja, está relacionada aos indivíduos caracterizados como autônomos, concentrados, disciplinados, persistentes, responsáveis e não impulsivos. 3. Extroversão: enquanto orientação de interesses e energia em direção ao mundo externo, pessoas ou objetos. $\mathrm{O}$ indivíduo considerado extrovertido apresenta características de autoconfiança, sociabilidade e entusiasmo. 4. Amabilidade: "definida como a tendência a agir de modo cooperativo e não egoísta" (p. 20). O individuo amável tem tendência em atuar em grupo, ressaltando características como cooperação, colaboração; tolerância, simpatia, modéstia e altruísmo. 5. Estabilidade emocional: "definida como a previsibilidade e consistência de reações emocionais, sem mudanças bruscas de humor" (p. 21), com destaque para atitudes de autocontrole, autoestima, calma e serenidade.

Para esses autores, os estudos sobre Big Five, que surgiram nos anos 30, sinalizam "a importância das competências socioemocionais para o aprendizado escolar e determinação do bem-estar ao longo da vida" [Santos e Primi 2014, p. 27]. A revisão de estudos elaborada pelos autores revelou que o desenvolvimento das competências socioemocionais contribui para que os alunos sejam mais criativos; assíduos às aulas e mais pontuais na entrega de trabalhos; tenham maior aproveitamento escolar; façam opção por cursos considerados mais difíceis; obtenham melhores notas nas avaliações escolares e permaneçam mais tempo na escola.

\footnotetext{
${ }^{1}$ http://www.educacaosec21.org.br/foruminternacional2014/
} 
CBIE-LACLO 2015

Anais dos Workshops do IV Congresso Brasileiro de Informática na Educação (CBIE 2015)

\section{ProUCA-TO: evidências da emergência de competências socioemocionais}

O ProUCA/UFT é um projeto de formação em rede, envolvendo profissionais das escolas municipais do Estado do Tocantins, desenvolvido de julho de 2013 a dezembro de 2014, em 135 escolas municipais de 74 municípios, que receberam os laptops do estado. Participaram da formação 2.065 cursistas entre professores e gestores das escolas e uma equipe de 144 formadores e tutores. Teve como intencionalidade a formação para uso pedagógico das TDIC e tem possibilitado a inclusão digital escolar e a apropriação tecnológica e pedagógica, enquanto linguagem, a partir dos laptops. Destacou a importância de repensar os currículos escolares rumo a um "web currículo" [Almeida 2014] que considere as demandas dos alunos, dos professores e da comunidade escolar, utilizando as TDIC como parceiras para potencializar os processos de ensino e de aprendizagem, promover o desenvolvimento de novas competências e utilizá-las a favor dos processos de formação, autoformação e do aprimoramento da qualidade de vida.

Nesse processo de formação ocorreram desdobramentos das ações que emergiram a partir de práticas pedagógicas, com o uso laptops, desenvolvidas pelos professores e alunos. Segundo Morin (1998), a emergência está no cerne dos processos auto-organizadores e aponta que todo estado global apresenta propriedades emergentes. A imprevisibilidade é um dos fundamentos do pensamento complexo em que "deve ser capaz de não apenas religar, mas de adotar uma postura em relação a incerteza" [Morin 1998, p. 8].

Neste trabalho, compreende-se que a emergência é aquilo que não estava previsto no design instrucional e no learning design [Piconez e Filatro 2009] do curso, mas que surgiu no decorrer do desenvolvimento do processo e que precisa ser considerado. Esse fenômeno foi observado na análise dos dados coletados em um questionário com perguntas abertas e fechadas, aplicado em 20 formadores e tutores, que atuaram nos municípios da regional de Araguaína-TO. Dentre os objetivos do instrumento estava a autoavaliação do formador e tutor e a avaliação do curso de formação. Nesse questionário houve também um espaço para comentar os resultados do desenvolvimento das atividades, apoiadas pelos laptops, realizadas pelos alunos de $1^{\circ}$ ao $5^{\circ}$ ano, de escolas de 14 municípios.

No processo de análise das respostas dos formadores (F) e tutores (T) foram encontradas algumas evidências de outras competências, não previstas no ProUCA/UFT, que estavam sendo desenvolvidas, a partir das práticas pedagógicas, com o uso dos laptops, no cotidiano da sala de aula. Na tentativa de explicitar o que emergiu dos questionamentos, os pesquisadores buscaram na Teoria dos Big Five [Santos e Primi 2014] relações que pudessem explicitar as emergências ocorridas. O Gráfico 1 relaciona a Teoria dos Big Five e as atitudes que emergiram, como desdobramentos do trabalho de formação dos professores junto aos alunos. 
CBIE-LACLO 2015

Anais dos Workshops do IV Congresso Brasileiro de Informática na Educação (CBIE 2015)

\section{Gráfico 1. Competências socioemocionais construídas pelos estudantes no ProUCA/UFT}

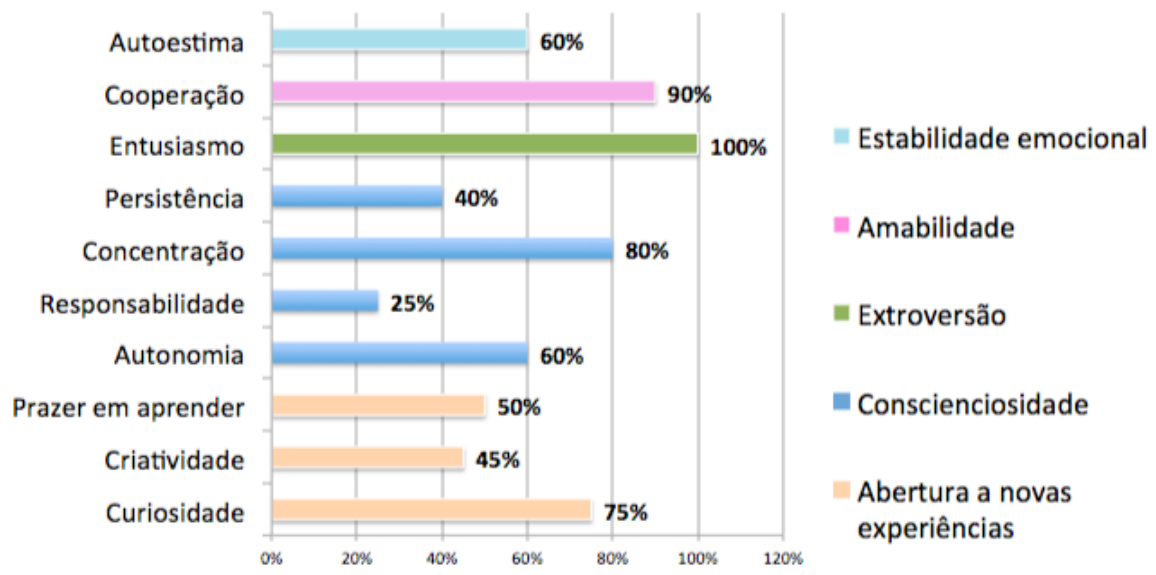

Para explicitar as competências que emergiram, foram analisados alguns excertos dos comentários dos sujeitos da pesquisa, que ilustram as relações das cinco grandes categorias das competências socioemocionais e suas respectivas atitudes, observadas no comportamento dos alunos do ProUCA/UFT.

Sobre a competência socioemocional "Extroversão", destacou-se o entusiasmo dos alunos ao desenvolverem as atividades com os laptops, pois $100 \%$ dos sujeitos da pesquisa apontaram esta atitude nos alunos, na realização das práticas pedagógicas, a partir das propostas do ProUCA/UFT, conforme apontam os excertos a seguir.

F1- As crianças ficaram animadas em poder levar os laptops para as visitas fora da escola.

T4- Na visita ao lixão, as crianças ficaram muito entusiasmadas e concentradas durante a entrevista com os funcionários que fazem a coleta de lixo. Elas perceberam que são responsáveis pela produção de menos lixo.

Sobre a competência "Amabilidade", 90\% dos participantes da pesquisa pontuaram a existência do trabalho cooperativo, colaborativo e de reconhecimento do outro como parceiro, em atividades desenvolvidas em grupos. Os excertos abaixo destacam a organização dos alunos para realizarem uma atividade proposta:

T11- Os alunos se organizaram em grupos para apresentar uma palestra sobre a segurança na internet para seus pais. Cada grupo teve autonomia para usar sua criatividade na apresentação. Eles ficaram animados e se sentiram importantes por estarem à frente dando as explicações!

Os excertos abaixo sinalizam a postura concentrada, persistente e autônoma dos alunos na realização das práticas pedagógicas motivadas pelo ProUCA/UFT, com o apoio das TDIC:

T5- Foi observada o entusiasmo e a concentração de uma aluna com deficiências física e intelectual na realização das atividades sobre meio ambiente que, mesmo com dificuldade, não desistiu da tarefa.

T13-Eles se conscientizaram da importância de manter a escola limpa e 


\section{CBIE-LACLO 2015}

Anais dos Workshops do IV Congresso Brasileiro de Informática na Educação (CBIE 2015)

tiveram a ideia de fazer um "mutirão da limpeza" nos espaços da escola.

Sobre a competência socioemocional "Abertura a novas experiências", $75 \%$ dos sujeitos da pesquisa asseguraram que as atividades do ProUCA/UFT potencializaram a curiosidade dos alunos; $50 \%$ afirmaram que o uso dos laptops estimularam o prazer em aprender e $45 \%$ destacaram que eles possibilitaram o exercício da criatividade. Nos excertos abaixo é possível encontrar as evidências de novas formas de realizar práticas pedagógicas prazerosas com as TDIC, que potencializem a curiosidade, entusiasmo, concentração e a criatividade dos alunos.

T9 - O ProUCA está transformando a escola e as atitudes dos alunos. Eles tiveram a iniciativa e a curiosidade de observar o céu à noite.

F4 - Os alunos pesquisaram com o laptop modelos de objetos que poderiam ser feitos com garrafas pet, caixas de leite. Foi percebida a criatividade, curiosidade na pesquisa do que poderia ser feito com os materiais recicláveis e concentração na elaboração dos artesanatos que foram expostos para a comunidade escolar.

Finalmente, sobre a competência "estabilidade emocional", $60 \%$ dos participantes pontuaram que as atividades desenvolvidas com o uso dos laptops promoveram a inclusão de alunos com deficiência e o aprimoramento da autoestima dos alunos. Nos excertos abaixo é possível constatar que, na proporção em que os alunos vão se apropriando das tecnologias, passam a ajudar o colega de forma solidária e responsável, alicerçado no conhecimento construído, que pode ser útil tanto ao colega quanto ao professor. Evidenciou-se também que o uso dos laptops tem contribuído para o surgimento de lideranças no próprio grupo, isto é, alunos que apresentam autocontrole, calma, serenidade e elevada autoestima.

T12- O ProUCA contribuiu para a formação de líderes na escola. Os alunos com mais domínio de tecnologias se tornaram monitores do ProUCA, pois tiveram a iniciativa de cooperar com os colegas e os próprios professores no desenvolvimento das atividades com o laptop

F6 - O uso do laptop tem contribuído com o envolvimento e desenvolvimento da autoestima dos alunos com deficiência.

É possível observar a relevância de duas competências socioemocionais com maior incidência junto aos alunos do ProUCA/TO: "Conscienciosidade", agregando a concentração (80\%), a autonomia (60\%), a persistência (40\%) e responsabilidade (25\%) e "Abertura a novas experiências", incluindo a curiosidade $(75 \%)$, o prazer em aprender $(50 \%)$ e criatividade $(45 \%)$.

O fato ganha destaque ao corroborar com Santos e Primi (2014, p. 19), ao afirmarem que "no que se refere à permanência na escola, a Conscienciosidade é, juntamente com a Abertura a Novas Experiências, o atributo mais associado à escolaridade final atingida por um indivíduo". 
CBIE-LACLO 2015

Anais dos Workshops do IV Congresso Brasileiro de Informática na Educação (CBIE 2015)

\section{Considerações finais}

Os resultados da pesquisa revelaram que as ações propostas e desenvolvidas pelos cursos de formação do ProUCA-UFT favoreceram o desenvolvimento de diferentes competências socioemocionais (Extroversão, Abertura a novas experiências, Estabilidade emocional, Amabilidade e Conscienciosidade), que emergiram no processo integração das TDIC no currículo escolar.

Este estudo preliminar apontou para a necessidade de aprofundamento das pesquisas sobre o desenvolvimento de competências socioemocionais em estudantes, participantes de projetos apoiados por TDIC. Tais competências podem contribuir para o fortalecimento da formação cognitiva, tão almejada pelas escolas, resultando na formação de estudantes capazes de comparar, refletir, analisar, sintetizar, criar, dentre outras habilidades intelectuais de ordem superior.

\section{Referências}

Almeida, M. E. B. (2014). "Integração currículo e tecnologias: concepção e possibilidades de criação de web currículo". In: Web currículo: aprendizagem, pesquisa e conhecimento com o uso de tecnologias digitais, Organizado por Almeida, M. E. B., Alves, R. M. e Lemos, S. D. V., Letra Capital, Rio de Janeiro.

Brasil. (1996) "Lei de Diretrizes e Bases n 9.394". http://www.planalto.gov.br/ccivil_03/LEIS/19394.htm, Abril, 2014.

Brasil. (2013) "Diretrizes Curriculares Nacionais Gerais da Educação Básica". http://www.portal.mec.gov.br, Maio 2015.

Carneiro, E. G.; Ziviani, C. R. (1998) A pessoa inteligente no mundo social. In Psicol. Esc. Educ., pags. 135-152. Publicação impressa.

Morin, E. (1998) "Complexidade e liberdade". https://pt.scribd.com/doc/137604126/MORIN-Edgar-Complexidade-e-Liberdade, Junho 2006.

OCDE. (2014) "Education and Social Progress". http://www.oecd.org/edu/ceri/ESPBrochure2014.pdf, Setembro 2014.

Piconez, S. C. B. e Filatro, A. (2009) O desenvolvimento profissional da docência na formação de professores face a utilização das tecnologias. In Educação Temática Digital, pags. 394-427. Publicação impressa.

Santos, D. e Primi, R. (2014) "Desenvolvimento socioemocional e aprendizado escolar: Uma proposta de mensuração para apoiar políticas públicas". https://educacaosec21.org.br, Setembro 2014.

UNESCO. (2008) "Padrões de competência em TIC para professores". https://unesdoc.unesco.org, Setembro 2014. 